\title{
Oxygen three-isotope ratios of silicate reference materials determined by direct comparison with VSMOW-oxygen
}

\author{
MinORU KUSAKABE ${ }^{1 *}$ and YUKIHIRO MATSUHISA ${ }^{2}$ \\ ${ }^{1}$ Institute for Study of the Earth's Interior, Okayama University, Misasa, Tottori 682-0193, Japan \\ ${ }^{2}$ Geological Survey of Japan, AIST, Bldg. \#7, Higashi 1-1-1, Tsukuba, Ibaraki 305-8567, Japan
}

(Received February 16, 2008; Accepted March 3, 2008)

\begin{abstract}
The $\delta^{17} \mathrm{O}$ and $\delta^{18} \mathrm{O}$ values of some international silicate reference materials such as NBS-28 quartz, NBS-30 biotite, UWG2 garnet, San Carlos olivine and some mineral separates of terrestrial origin were re-evaluated on the VSMOWSLAP scale using the $\mathrm{CO}_{2}$-laser fluorination technique. To report their $\delta^{18} \mathrm{O}$ values on the VSMOW-SLAP scale, the $\delta^{17} \mathrm{O}$ and $\delta^{18} \mathrm{O}$ values of $\mathrm{O}_{2}$ directly derived from VSMOW and SLAP were measured using the same preparation line as used for the silicates. Application of the VSMOW-SLAP scale to the above silicate reference samples resulted in the $\delta^{18} \mathrm{O}$ values of NBS-28 quartz, NBS-30 biotite, UWG2 garnet and San Carlos olivine that are 9.18, 4.88, 5.59 and 5.28\%o, respectively. The data form a straight line in the $10^{3} \ln \left(1+\delta^{17} \mathrm{O} / 10^{3}\right)$ vs. $10^{3} \ln \left(1+\delta^{18} \mathrm{O} / 10^{3}\right)$ plot with a slope of $0.526 \pm$ 0.003 (standard error at $95 \%$ confidence limit), but the line for the waters (VSMOW, GISP, SLAP and MSA-6) seems to have a slightly steeper slope of $0.528 \pm 0.001$, although difference of the slopes is not statistically significant.
\end{abstract}

Keywords: oxygen three-isotope ratios, silicate reference materials, VSMOW-SLAP normalization, terrestrial fractionation line, $\mathrm{BrF}_{5}$ fluorination

\section{INTRODUCTION}

Oxygen isotopic ratios of natural materials of geochemical interest are nowadays reported relative to Vienna Standard Mean Ocean Water or VSMOW (Coplen, 1995). The VSMOW-scale for reporting oxygen isotopic ratios of silicates and oxides contains ambiguity as large as $0.5 \%$ due mainly to various procedures of oxygen extraction from samples and the method of defining the VSMOW-scale in individual laboratories. For water samples oxygen isotopic comparison between a sample and VSMOW is precisely done by means of the $\mathrm{CO}_{2}-\mathrm{H}_{2} \mathrm{O}$ equilibration method (Epstein and Mayeda, 1953), because the equilibrium fractionation factor of oxygen isotopes between $\mathrm{CO}_{2}$ and $\mathrm{H}_{2} \mathrm{O}\left(\alpha_{\mathrm{CO} 2-\mathrm{H} 2 \mathrm{O}}\right)$ is cancelled out as long as the equilibration is performed at a constant temperature. For silicates and oxides, however, the situation is different. Oxygen is liberated from samples in the form of $\mathrm{O}_{2}$ using fluorination techniques (Clayton and Mayeda, 1963; Sharp, 1990; and later development summarized in Taylor, 2005). Many workers convert this $\mathrm{O}_{2}$

\footnotetext{
*Corresponding author (e-mail: mhk2314@hotmail.com)

*Present address: Korea Polar Research Institute, KORDI, Songdo Techno Park, 7-50, Songdo-dong, Yeonsu-gu, Incheon 406-840, Korea.

Copyright (c) 2008 by The Geochemical Society of Japan.
}

to $\mathrm{CO}_{2}$ to compare its oxygen isotopic ratio with $\mathrm{CO}_{2}$ that has been equilibrated with reference water of a known isotopic composition (such as VSMOW). In this comparison, the equilibrium fractionation factor $\alpha_{\mathrm{CO} 2-\mathrm{H} 2 \mathrm{O}}$ comes into the calculation. Since the reported values of $\alpha_{\mathrm{CO} 2-}$ $\mathrm{H} 2 \mathrm{O}$ at $25^{\circ} \mathrm{C}$ range from 1.0407 to 1.0412 (Friedman and O'Neil, 1977; Chako et al., 2001), this variability causes serious uncertainty in $\delta^{18} \mathrm{O}$ values of minerals relative to VSMOW, if the oxygen isotopic ratios are determined using $\mathrm{CO}_{2}$ as an analytical gas for mass spectrometry. To avoid the ambiguity, direct comparison of $\mathrm{O}_{2}$ liberated from reference water samples with that from minerals is preferable. In the present note, we show the results of oxygen isotopic ratios of some international reference minerals by direct comparison of oxygen isotopic ratios of VSMOW and SLAP.

\section{Analitical Procedures}

Oxygen was extracted in the form of $\mathrm{O}_{2}$ from silicate and oxide minerals using a laser fluorination system with $\mathrm{BrF}_{5}$ as a reagent (Sharp, 1990). The laser used in our system was a $\mathrm{CO}_{2}$ laser with a maximum power of $12 \mathrm{~W}$ and the wavelength of $10.6 \mu \mathrm{m}$ (Model JLC-1259, Japan Laser). The focal length was $10.2 \mathrm{~cm}$ and a minimum spot diameter was $100 \mu \mathrm{m}$. A visible, coaxial $\mathrm{He}-\mathrm{Ne}$ laser (wavelength of $633 \mathrm{~nm}$ ) was attached to locate a target. The technical details of the laser fluorination system have 
been described by Kusakabe et al. (2004). The system consists basically of metal and glass parts; the reaction chamber and the purification line made of stainless steel (SUS316), and the purification line made of Pyrex ${ }^{\circledR}$ glass after the fluorination gases have been removed. The end of the glass line is connected on-line to the inlet system of an isotope ratio mass spectrometer equipped with triple collectors (modified SIRA12, VG Micromass). The modification of SIRA12 included (1) replacement of all electronic units (high voltage supply, source control unit, and vacuum gauge control) with modern ones supplied by Europa Scientific (UK), (2) replacement of the original dual inlet system with hand-made, dual mercury Toepler pumps, (3) replacement of the original solenoid type change-over valve with a pneumatically operated Kel-F seated micro inlet (VG Micromass), and (4) installation of WinIRMS, a Windows-based data acquisition software (Etchells, pers. commun.). With the micro inlet, the cross-seat leakage of reference and sample gases is negligible. The instrumental factors such as the effects of tailing of $\mathrm{m} / \mathrm{z} 32$ and of background on $\mathrm{m} / \mathrm{z} 33$ were evaluated following the method described by Horibe (1966). The intensity ratio of the $m / z 32$ tailing to the $\mathrm{m} / \mathrm{z} 33$ output was $\sim 3 \times 10^{-3}$, and the background over $\mathrm{m} / \mathrm{z} 33$ was $\sim 8 \times 10^{-4}$ based on the replicate analysis. Thus ${ }^{17} \mathrm{O} /{ }^{16} \mathrm{O}$ and ${ }^{18} \mathrm{O} /{ }^{16} \mathrm{O}$ ratios are calculated from simultaneous measurement of $\mathrm{m} / \mathrm{z} 33 / 32$ and $34 / 32$ beam intensity ratios after the instrumental corrections. The $\mathrm{O}_{2}$ from sample was measured against a working standard $\mathrm{O}_{2}$ gas which is commercially available and $99.999 \%$ pure. The working standard has $\delta^{17} \mathrm{O}$ and $\delta^{18} \mathrm{O}$ values of $14.59 \%$ and $28.34 \%$ with respect to VSMOW, respectively, with a ${ }^{17} \mathrm{O}$ excess of $-0.28 \%$ relative to the terrestrial fractionation line, which indicates its tropospheric origin (Miller, 2002).

Approximately $2 \mathrm{mg}$ of sample was used for the analysis of silicate and oxide minerals. The sample was placed in a hole of a sample holder made of $\mathrm{Ni}$, which was held in the reaction chamber. In our system, 8 samples can be loaded in a reaction chamber at one time. The samples were preheated at $\sim 180^{\circ} \mathrm{C}$ for several hours to overnight. Pre-fluorination at room temperature was applied for several hours to overnight (depending on mineral type) to remove any atmospheric moisture adsorbed on the surface of the sample, reaction chamber and $\mathrm{a} \mathrm{BaF}_{2}$ window. Bromine pentafluoride gas of about $300 \mathrm{hPa}$ was used for the fluorination reaction using the laser as a heat source. Reaction was visually observed through a binocular microscope. After purification of $\mathrm{O}_{2}$ gas through a series of cryogenic traps and a $\mathrm{KBr}$ trap for $\mathrm{F}_{2}$ removal, purified $\mathrm{O}_{2}$ was finally adsorbed in a calibrated cold finger containing Molecular Sieve 13X at liquid nitrogen temperature. From the pressure of $\mathrm{O}_{2}$ gas released from the Molecular Sieve $13 \mathrm{X}$ cold finger at room temperature, the

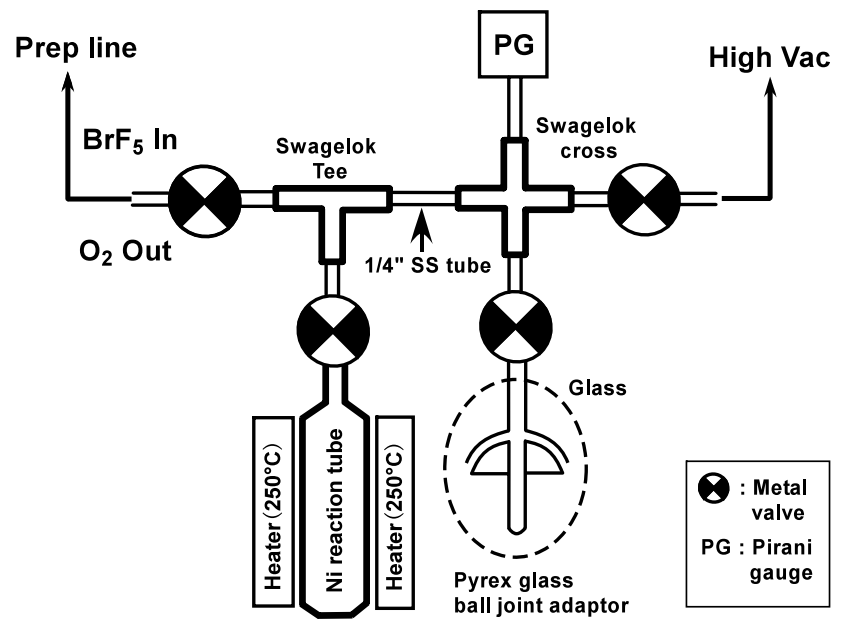

Fig. 1. Ni reaction tube used to decompose water to $\mathrm{O}_{2}$ by reaction with $\mathrm{BrF}_{5}$. Two $\mathrm{mg}$ of water was taken in the Pyrex glass ball joint adaptor using a micro syringe. After evacuation of air the water was thoroughly distilled into the Ni reaction tube. Reaction temperature and duration were $250{ }^{\circ} \mathrm{C}$ and 60 minutes, respectively.

reaction yield was calculated before isotopic measurement by the mass spectrometer.

For analysis of water samples the reaction chamber for minerals was replaced by a small $\mathrm{Ni}$ reaction tube with a capacity of $25 \mathrm{ml}$ (Fig. 1). Two $\mu \mathrm{l}$ of water sample was distilled into the $\mathrm{Ni}$ reaction tube and reacted with $\mathrm{BrF}_{5}$ at $250^{\circ} \mathrm{C}$ for $60 \mathrm{~min}$ to liberate oxygen. The oxygen was purified in the same manner as $\mathrm{O}_{2}$ from minerals. A commercially available stainless steel reaction tube used in an early stage of the water fluorination runs was found to give a poor reproducibility of $\delta$ values due probably to progressive fluoride formation on inner wall of the reaction tube, and thus abandoned.

\section{RESULTS AND DISCUSSION}

$\delta$ notation was originally used as deviation in parts per thousand (permil) from those of Standard Mean Ocean Water (SMOW) (Craig, 1961) to report ${ }^{18} \mathrm{O} /{ }^{16} \mathrm{O}$ ratio of sample. It was defined as $\delta^{18} \mathrm{O}(\%)=\left(R_{\mathrm{S}} / R_{\mathrm{SMOW}}-1\right) \times$ 1000 , where $R_{\mathrm{S}}$ and $R_{\mathrm{SMOW}}$ are the ${ }^{18} \mathrm{O} /{ }^{16} \mathrm{O}$ ratios of sample and SMOW, respectively. The $\delta$ notation is also used to report the ${ }^{17} \mathrm{O} /{ }^{16} \mathrm{O}$ ratios. Since real $\mathrm{SMOW}$ is nonexistent, VSMOW (Vienna-SMOW distributed by IAEA, Vienna) which is essentially the same as SMOW in the ${ }^{18} \mathrm{O} /{ }^{16} \mathrm{O}$ and $D / H$ ratios is taken as the standard (Gonfiantini, 1984; Hut, 1987). The absolute values of $\left({ }^{18} \mathrm{O} /{ }^{16} \mathrm{O}\right)_{\text {Vsmow }}$ and $\left({ }^{17} \mathrm{O} /{ }^{16} \mathrm{O}\right)_{\text {Vsmow }}$ have been reported to be $(2005.20 \pm 0.45) \times 10^{-6}$ (Baertschi, 1976) and (379.9 $\pm 0.8) \times 10^{-6}(\mathrm{Li}$ et al., 1988), respectively. In the present 
Table 1. $\delta^{17} O$ and $\delta^{18} O$ values of reference waters and minerals on the VSMOW-SLAP scale

\begin{tabular}{|c|c|c|c|c|c|c|c|c|c|}
\hline Sample & $\begin{array}{c}\text { Number of } \\
\text { analysis }\end{array}$ & $\delta^{17} \mathrm{O}_{\mathrm{wst}}$ & $1 \sigma^{(a)}$ & $\delta^{18} \mathrm{O}_{\mathrm{wst}}$ & $1 \sigma^{(\mathrm{a})}$ & $\delta^{17} \mathrm{O}_{\text {vSMOW }^{(b)}}$ & $\delta^{18} \mathrm{O}_{\text {VSMOW }^{(b)}}$ & $10^{3} \ln \left[1+\delta^{17} \mathrm{O}_{\text {vSMOW }} * 10^{-3}\right]$ & $10^{3} \ln \left[1+\delta^{18} \mathrm{O}_{\text {vSMOW }} * 10^{-3}\right]$ \\
\hline \multicolumn{10}{|l|}{ Waters } \\
\hline VSMOW & 7 & -14.15 & 0.04 & -27.13 & 0.06 & 0.00 & 0.00 & 0.00 & 0.00 \\
\hline SLAP & 5 & -42.95 & 0.07 & -80.30 & 0.06 & -29.21 & -54.65 & -29.64 & -56.20 \\
\hline GISP & 6 & -26.88 & 0.08 & -50.88 & 0.07 & -12.91 & -24.41 & -12.99 & -24.72 \\
\hline MSA6 & 2 & -18.30 & - & -35.06 & - & -4.21 & -8.15 & -4.21 & -8.19 \\
\hline \multicolumn{10}{|l|}{ Minerals } \\
\hline NBS-28 quartz & 20 & -9.46 & 0.06 & -18.34 & 0.07 & 4.76 & 9.04 & 4.75 & 9.00 \\
\hline NBS-30 biotite & 7 & -11.62 & 0.08 & -22.45 & 0.08 & 2.57 & 4.81 & 2.57 & 4.80 \\
\hline UWG-2 garnet & 94 & -11.28 & 0.08 & -21.78 & 0.10 & 2.91 & 5.50 & 2.91 & 5.48 \\
\hline San Carlos olivine & 7 & -11.35 & 0.08 & -22.08 & 0.09 & 2.84 & 5.19 & 2.84 & 5.18 \\
\hline Augite & 5 & -11.23 & 0.05 & -21.71 & 0.11 & 2.97 & 5.57 & 2.96 & 5.55 \\
\hline Enstatite & 5 & -9.37 & 0.12 & -18.23 & 0.13 & 4.85 & 9.15 & 4.84 & 9.11 \\
\hline Fayalite & 6 & -11.24 & 0.10 & -21.89 & 0.12 & 2.96 & 5.39 & 2.95 & 5.37 \\
\hline Forsterite & 5 & -8.79 & 0.04 & -16.97 & 0.03 & 5.44 & 10.44 & 5.43 & 10.39 \\
\hline Magnetite & 4 & -17.43 & 0.04 & -33.30 & 0.07 & -3.32 & -6.35 & -3.33 & -6.37 \\
\hline Zircon & 6 & -15.91 & 0.06 & -30.44 & 0.06 & -1.78 & -3.40 & -1.78 & -3.41 \\
\hline Juan de Fuca basalt glass & 37 & -11.42 & 0.07 & -22.03 & 0.12 & 2.77 & 5.24 & 2.77 & 5.23 \\
\hline Working standard $\left(\mathrm{O}_{2}\right)$ & & & & & & 14.36 & 27.89 & 14.26 & 27.50 \\
\hline
\end{tabular}

\begin{tabular}{|c|c|c|c|c|c|}
\hline Sample & $10^{3} \ln \left[1+\delta^{17} \mathrm{O}_{\text {vSMOW-SLAP }} * 10^{-3}\right]$ & $10^{3} \ln \left[1+\delta^{18} \mathrm{O}_{\text {VSMOW-SLAP }} * 10^{-3}\right]$ & $\delta^{17} \mathrm{O}_{\mathrm{VSMOW}-\mathrm{SLAP}}{ }^{(\mathrm{c})}$ & $\delta^{18} \mathrm{O}_{\text {VSMOW-SLAP }}^{(\mathrm{c})}$ & $\Delta^{17} \mathrm{O}_{\mathrm{M}}^{(\mathrm{d})}$ \\
\hline \multicolumn{6}{|l|}{ Waters } \\
\hline VSMOW & 0.00 & 0.00 & 0.00 & 0.00 & 0.00 \\
\hline SLAP & -30.12 & -57.10 & -29.67 & -55.50 & 0.04 \\
\hline GISP & -13.20 & -25.11 & -13.11 & -24.80 & 0.07 \\
\hline MSA6 & -4.28 & -8.32 & -4.27 & -8.28 & 0.11 \\
\hline \multicolumn{6}{|l|}{ Minerals } \\
\hline NBS-28 quartz & 4.83 & 9.14 & 4.84 & 9.18 & 0.01 \\
\hline NBS-30 biotite & 2.61 & 4.87 & 2.61 & 4.88 & 0.04 \\
\hline UWG-2 garnet & 2.95 & 5.57 & 2.96 & 5.59 & 0.02 \\
\hline San Carlos olivine & 2.89 & 5.26 & 2.89 & 5.28 & 0.12 \\
\hline Augite & 3.01 & 5.64 & 3.02 & 5.66 & 0.04 \\
\hline Enstatite & 4.92 & 9.25 & 4.93 & 9.30 & 0.05 \\
\hline Fayalite & 3.00 & 5.46 & 3.01 & 5.47 & 0.13 \\
\hline Forsterite & 5.52 & 10.55 & 5.53 & 10.61 & -0.04 \\
\hline Magnetite & -3.38 & -6.47 & -3.38 & -6.45 & 0.02 \\
\hline Zircon & -1.81 & -3.46 & -1.81 & -3.45 & 0.01 \\
\hline Juan de Fuca basalt glass & 2.81 & 5.31 & 2.81 & 5.33 & 0.01 \\
\hline Working standard $\left(\mathrm{O}_{2}\right)$ & 14.48 & 27.95 & 14.59 & 28.34 & -0.28 \\
\hline
\end{tabular}

${ }^{(a)}$ Standard deviation of the distribution of analyses of each sample including chemical preparation.

${ }^{(b)} \delta^{17} O_{V S M O W}$ and $\delta^{18} O_{V S M O W}$ are calculated from $\delta^{17} O_{\text {wst }}$ and $\delta^{18} O_{\text {wst }}$, respectively.

${ }^{(c)} \delta^{17} O_{V S M O W-S L A P}$ and $\delta^{18} O_{V S M O W-S L A P}$ were obtained after normalizing $10^{3} \ln \left[10^{-3} \delta^{18} O_{V S M O W-S L A P}-1\right]$ to -30.12 and $10^{3} \ln \left[10^{-3} \delta^{18} O_{V S M O W-S L A P}\right.$ $-1]$ to -57.10 , respectively. -57.10 is $10^{3} \ln \left(1+(-55.50) * 10^{-3}\right)$, and -30.12 is $10^{3} \ln \left(1+\delta^{17} O_{S M O W^{*}} 10^{-3}\right)$ of SLAP multiplied by $(-57.10 /-$ 56.20).

(d) $\Delta^{17} O_{M}$ is the offset from a reference fractionation line (calculated according to Miller, 2002). Slope values of 0.5282 and 0.5263 were used for waters and silicates, respectively, using isotopic data scaled to VSMOW-SLAP.

study, we have measured ${ }^{18} \mathrm{O} /{ }^{16} \mathrm{O}$ and ${ }^{17} \mathrm{O} /{ }^{16} \mathrm{O}$ ratios of $\mathrm{O}_{2}$ recovered from international reference water samples, i.e., VSMOW, SLAP and GISP, and from some international reference silicate minerals, to report their $\delta$ values on the VSMOW-SLAP normalized scale as recommended by IAEA (Gonfiantini, 1978; Coplen, 1988, both recom- mended only for $\delta^{18} \mathrm{O}$ ). Some of the samples analyzed here are widely used for inter-laboratory comparison of oxygen isotopic ratios of silicate minerals and rocks. They include NBS-28 quartz, NBS-30 biotite, UWG-2 garnet, and San Carlos olivine. Some mineral separates of forsterite, fayalite, enstatite, augite, magnetite, zircon, and 
basalt glass from the Juan de Fuca Ridge were also analyzed to examine the ${ }^{18} \mathrm{O} /{ }^{16} \mathrm{O}-{ }^{17} \mathrm{O} /{ }^{16} \mathrm{O}$ relationship for terrestrial materials. The analytical results are given in Table 1 . The reproducibility of the $\delta^{17} \mathrm{O}$ and $\delta^{18} \mathrm{O}$ measurements of silicates and oxides is generally smaller than $\pm 0.1 \%$ as evaluated through 94 replicate analyses of UWG-2 garnet which was found to be $\pm 0.08 \%$ for $\delta^{17} \mathrm{O}$ and $\pm 0.09 \%$ for $\delta^{18} \mathrm{O}$ (one sigma of the distribution of analyses including chemical preparation). The reproducibility applies to the period of more than a year. It was better than $\pm 0.1 \%$ o for waters (Table 1 ).

The $\delta^{17} \mathrm{O}_{\text {VSMOW }}$ and $\delta^{18} \mathrm{O}_{\text {vsmow }}$ values in Table 1 were calculated relative to ${ }^{17} \mathrm{O} /{ }^{16} \mathrm{O}$ and ${ }^{18} \mathrm{O} /{ }^{16} \mathrm{O}$ ratios of $\mathrm{O}_{2}$ directly derived from VSMOW and SLAP and thus VSMOW-SLAP scaled, following the procedures stated later. The VSMOW-SLAP scaling to any sample has been recommended in order to eliminate an instrumental bias characteristic to a mass spectrometer used. In other words, the measured $\delta^{18} \mathrm{O}$ value of SLAP should be normalized to $-55.50 \%$ (Gonfiantini, 1978: Coplen, 1988). The scaling factor calculated from the $\delta^{18} \mathrm{O}$ measurement can be applied to $\delta^{17} \mathrm{O}$, because a good linearity is guaranteed when $\delta^{17} \mathrm{O}$ and $\delta^{18} \mathrm{O}$ are plotted on the $10^{3} \ln \left(1+\delta^{17} \mathrm{O} /\right.$ $\left.10^{3}\right)$ vs. $10^{3} \ln \left(1+\delta^{18} \mathrm{O} / 10^{3}\right)$ space (Miller, 2002). We assumed the VSMOW-SLAP scaling factors are applicable to silicates that have usually $\delta$ values higher than waters.

The $\delta^{18} \mathrm{O}$ values of NBS-28 quartz, NBS-30 biotite, UWG-2 garnet and San Carlos olivine obtained by different laboratories were compared (Table 2). The range of reported $\delta^{18} \mathrm{O}$ values of NBS-28 quartz is surprisingly big, i.e., 8.8 to $10.0 \%$. The variability results from different methods of oxygen extraction, choice of analytical gas for mass spectrometric analysis and whether the VSMOW-SLAP scaling has been applied (mostly not). Historically, $\mathrm{O}_{2}$ was extracted using $\mathrm{BrF}_{5}$ as a fluorination reagent in an externally heated Ni reaction tube (e.g., Clayton and Mayeda, 1963). The use of an infrared laser as a heating device was later introduced (Sharp, 1990). Laser heating has become popular because it has advantages to give temperatures high enough to decompose most refractory minerals under $\mathrm{BrF}_{5}$ atmosphere and to give high analytical efficiency. The choice of an external or laser heating does not matter for decomposition of quartz which reacts with $\mathrm{BrF}_{5}$ at temperatures as low as $500^{\circ} \mathrm{C}$. Many researchers who are interested only in $\delta^{18} \mathrm{O}$ values convert $\mathrm{O}_{2}$ to $\mathrm{CO}_{2}$ for isotopic analysis with a mass spectrometer. The isotopic composition of the $\mathrm{CO}_{2}$ is then compared with that of $\mathrm{CO}_{2}$ that has been equilibrated with a reference water like VSMOW. The oxygen isotopic fractionation factor between $\mathrm{CO}_{2}$ and water $\left(\alpha_{\mathrm{CO} 2-\mathrm{H} 2 \mathrm{O}}\right)$ has to be applied to calculate $\delta^{18} \mathrm{O}$ values of silicates and oxides relative to VSMOW from measured $\mathrm{m} / \mathrm{z} 46 / 44$ ratios of the equilibrated $\mathrm{CO}_{2}$. It should be noted that the value of $\alpha_{\mathrm{CO} 2-\mathrm{H} 2 \mathrm{O}}$ has not been agreed upon among re- searchers; it ranges from 1.0407 to 1.0417 at $25^{\circ} \mathrm{C}$ (summarized by Chako et al., 2001), resulting in an uncertainty of silicate $\delta^{18} \mathrm{O}$ as much as $\pm 0.5 \%$. It should also be noted that many papers describing silicate $\delta^{18} \mathrm{O}$ values obtained through the $\mathrm{CO}_{2}$ method do not mention which of the $\mathrm{CO}_{2}-\mathrm{H}_{2} \mathrm{O}$ fractionation factors was used. This makes the choice of the best $\delta^{18} \mathrm{O}$ value for NBS-28 quartz difficult on the VSMOW scale. Valley et al. (1995) recommended a $\delta^{18} \mathrm{O}$ value of $+5.8 \%$ relative to VSMOW for UWG-2, a garnet standard now widely used as a reference for oxygen isotopic analysis of silicates by laser fluorination techniques. For the $\delta^{18} \mathrm{O}$ value of UWG-2 garnet on the VSMOW-scale, they assumed $+9.59 \pm$ $0.12 \%$ for NBS-28 based on a compilation of literature values reported by various laboratories (Hut, 1987; Gonfiantini et al., 1995). In the data compilation, it is not clear which methods were used for determining the VSMOW-scale in individual laboratories.

As shown in Table 2, our $\delta^{18} \mathrm{O}$ values of NBS-28 quartz, NBS-30 biotite, UWG-2 garnet and San Carlos olivine relative to VSMOW (VSMOW-SLAP scaled) were $9.18 \pm 0.07 \%$ o $(1 \sigma, n=20),+4.88 \pm 0.08 \%$ o $(n=7),+5.59$ $\pm 0.09 \%$ o $(n=94)$ and $+5.28 \pm 0.10 \%$ ( $n=7)$, respectively. These standard deviations for the above samples will reduce to $0.02,0.03,0.01$, and $0.04 \%$, respectively, if expressed in the standard error of the mean of the measurements. The use of $\mathrm{O}_{2}$ directly converted from VSMOW in the scaling reduces the uncertainties mentioned above. It is noted that the $\delta^{18} \mathrm{O}$ values of NBS quartz obtained using $\mathrm{O}_{2}$ as the analytical gas are generally lower than those using $\mathrm{CO}_{2}$. The $\delta^{18} \mathrm{O}$ values of $9.23 \sim 9.43 \%$ o have been reported for NBS-28 quartz when $\mathrm{O}_{2}$ directly derived from VSMOW is used as reference (Clayton and Mayeda, 1983; Rumble and Hoering, 1994; Jabeen and Kusakabe, 1997; Miller et al., 1999). The $\delta^{18} \mathrm{O}$ values of 9.22 9.34\% have been obtained for NBS-28 quartz with the conventional technique with $\alpha_{\mathrm{CO} 2-\mathrm{H} 2 \mathrm{O}}=1.0407\left(25^{\circ} \mathrm{C}\right)$ (Ito and Clayton, 1983; Matsuhisa and Aoki, 1993). Coplen et al. (1983) suggested that the $\delta^{18} \mathrm{O}$ value of NBS28 quartz would be $9.19 \%$ if $\alpha_{\mathrm{CO} 2-\mathrm{H} 2 \mathrm{O}}=1.04073\left(25^{\circ} \mathrm{C}\right)$ is used, and similarly the value for NBS-30 biotite would be $4.65 \%$. As has been mentioned before, Valley et al. (1995) recommended a $\delta^{18} \mathrm{O}$ value of $5.8 \%$ for UWG-2 garnet by normalizing their data for NBS-28 quartz to $\delta^{18} \mathrm{O}=9.59 \%$, which was compiled by IAEA (Hut, 1987; Gonfiantini et al., 1995). However, Table 1 of Valley et al. (1995) shows that the average $\delta^{18} \mathrm{O}$ value for UWG-2 reported on their own SMOW scale is $5.59 \%$, which is identical to the value obtained by the present study. Table 1 of Valley et al. (1995) also shows that the average $\delta^{18} \mathrm{O}$ value for NBS-28 is $9.29 \%$, which is closer to our value than to the IAEA value. Integrating above, the $\delta^{18} \mathrm{O}$ value of $9.58 \%$ for NBS-28 quartz compiled by IAEA (Hut, 1987; Gonfiantini et al., 1995) appears to be too 


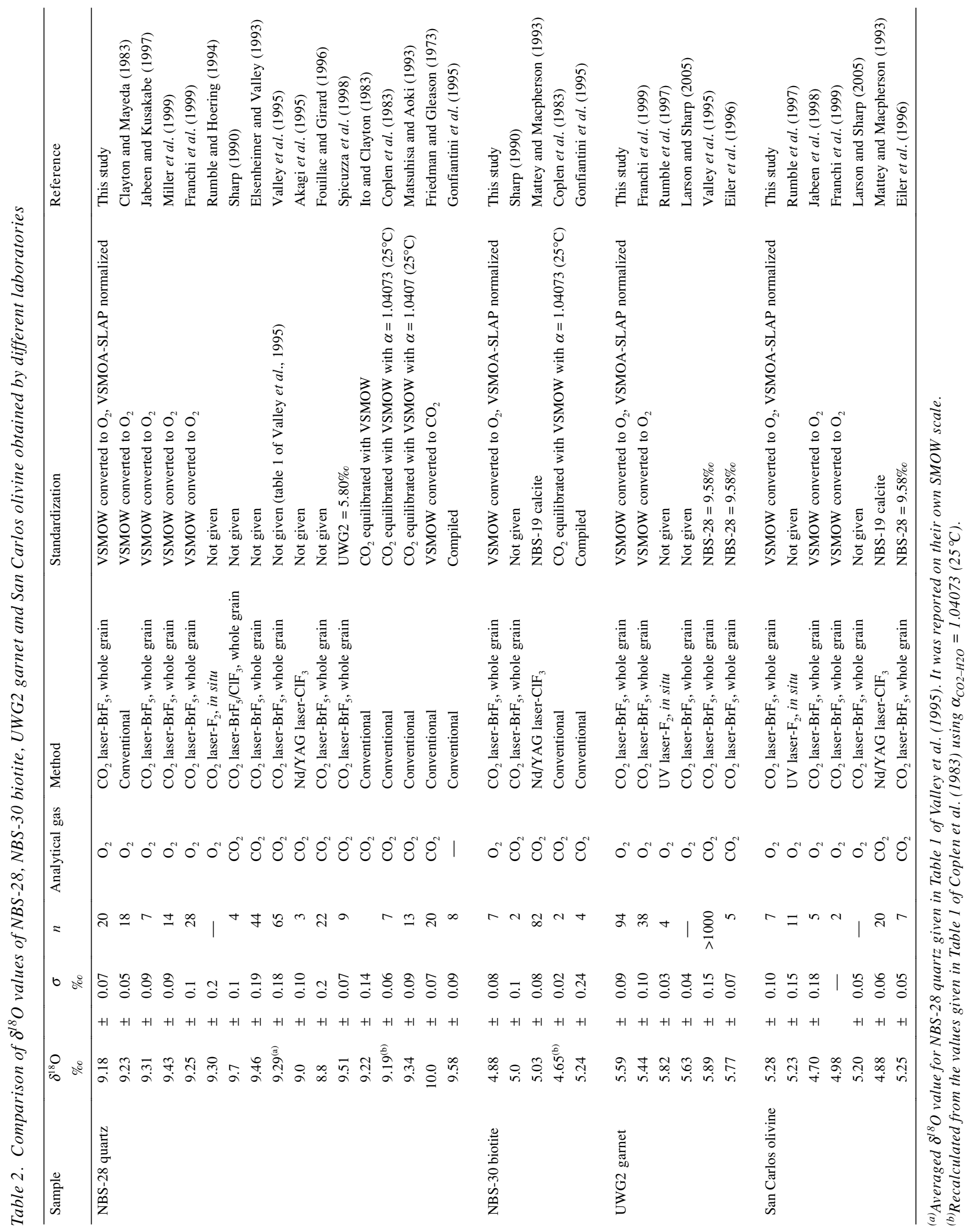



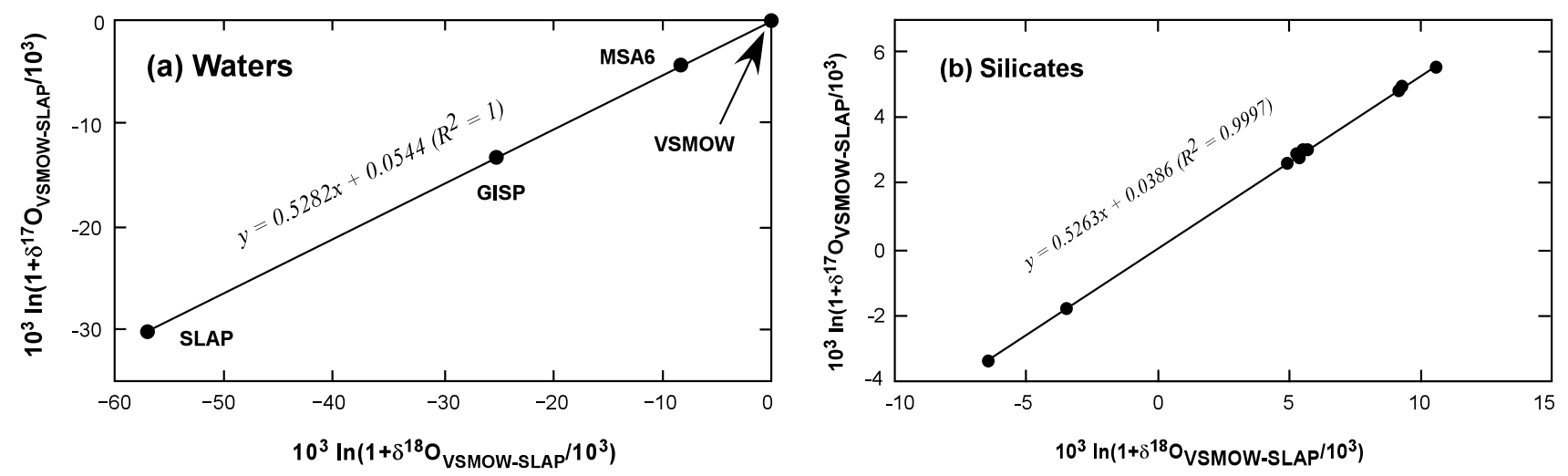

Fig. 2. (a) Regression of $10^{3} \ln \left(1+\delta^{17} O_{V S M O W-S L A P} / 10^{3}\right) v s .10^{3} \ln \left(1+\delta^{18} O_{V S M O W-S L A P} / 10^{3}\right)$ plot for waters (VSMOW, SLAP, GISP and MSA-6) using the averaged values shown in Table 1. The slope 0.528 is associated with the standard error of \pm 0.001 . (b) Regression of $10^{3} \ln \left(1+\delta^{I 7} O_{V S M O W-S L A P} / 10^{3}\right)$ vs. $10^{3} \ln \left(1+\delta^{18} O_{V S M O W-S L A P} / 10^{3}\right)$ plot for silicates and oxides using the averaged values shown in Table 1. The slope 0.526 is associated with the standard error of \pm 0.003 .

high by $\sim 0.4 \%$. We recommend to accumulate more $\delta^{18} \mathrm{O}$ data of reference silicate materials based on the $\mathrm{O}_{2}$ method, and to use $\alpha_{\mathrm{CO} 2-\mathrm{H} 2 \mathrm{O}}=1.04073\left(25^{\circ} \mathrm{C}\right)$ if $\delta^{18} \mathrm{O}$ is calculated via $\mathrm{CO}_{2}$ equilibrated with VSMOW.

We also measured $\delta^{17} \mathrm{O}$ values for the samples in Table 1 . The relationship between $\delta^{17} \mathrm{O}$ and $\delta^{18} \mathrm{O}$ of terrestrial minerals and rocks are known to form a "terrestrial fractionation line", approximated by $\delta^{17} \mathrm{O}=0.52 \times \delta^{18} \mathrm{O}$ (Clayton et al., 1973; Clayton, 1993). The slope of the line 0.52 represents a best fit value for natural rocks and waters including some theoretical considerations (Matsuhisa et al., 1978). Our mineral data in Table 1 just plot on the terrestrial fractionation line (Kusakabe et al., 2004), confirming the above relationship. Recently, Miller (2002) has noted that the linearity of this massdependent relationship is only satisfactory when the range of $\delta^{18} \mathrm{O}$ values is within those normally encountered in terrestrial and extraterrestrial minerals and rocks. He stresses that the linearity is really guaranteed if the data are plotted in the $10^{3} \ln \left(1+\delta^{17} \mathrm{O} / 10^{3}\right)$ vs. $10^{3} \ln \left(1+\delta^{18} \mathrm{O} /\right.$ $10^{3}$ ) space. The regression equation with a proportionality constant " $\lambda$ " is linear for a much wider range of delta values. Miller proposes $\lambda=0.5247 \pm 0.0007$ for terrestrial silicates based on 104 data points (47 samples) that span from $\delta^{18} \mathrm{O}=-15 \sim+24 \%$ o relative to the reference gas used by Miller et al. (1999). A recent inter-laboratory comparison of hydrothermal quartz that has a range in $\delta^{18} \mathrm{O}$ of $31 \%$ yielded very good agreement of $\lambda$ values of $0.5240 \sim 0.5242$ regardless of the difference in mass spectrometers used and in analytical techniques (Rumble et al., 2007). A similar value of 0.5237 for terrestrial rocks and minerals has been reported by Pack et al. (2007). A slightly higher $\lambda$ value of $0.526 \pm 0.001$ has been suggested for garnet from high $P-T$ metamorphic facies by Rumble et al. (2007).
The $\lambda$ values for water samples, however, appear to be higher than those for silicates. Meijer and Li (1998) published a $\lambda$ value of $0.5281 \pm 0.0015$ for meteoric waters (VSMOW and SLAP included), with $\delta^{18} \mathrm{O}$ ranging from -55 to $+9 \%$. A similar value of $0.527 \pm 0.002$ can be calculated using the data for VSMOW, GISP and SLAP in Jabeen and Kusakabe (1997). Recently Barkan and Luz (2005) have shown a very similar value of $\lambda=0.5279 \pm$ 0.0001 for VSMOW, GISP and SLAP using their very precise data set. A significantly lower value of 0.5179 has been reported for oxygen involved in respiration pathways (Luz and Barkan, 2005).

We evaluated our $\lambda$ values for waters and silicates using the data in Table 1 which shows the mean values for each sample. The procedures are as follows. First, raw $\delta^{17} \mathrm{O}$ and $\delta^{18} \mathrm{O}$ values relative to the working standard gas were converted to $\delta^{17} \mathrm{O}_{\mathrm{VSMOW}}$ and $\delta^{18} \mathrm{O}_{\mathrm{VSMOW}}$ values (columns 7 and 8 ). The $\delta^{17} \mathrm{O}_{\text {VsMow }}$ and $\delta^{18} \mathrm{O}_{\text {VsMow }}$ values were then converted to a logarithmic format, i.e., $10^{3}$ $\ln \left(1+\delta^{i} \mathrm{O} / 10^{3}\right)$ (where $i$ is 17 or 18 . See columns 9 and $10)$. Since very good linearity is guaranteed in the $10^{3}$ $\ln \left(1+\delta^{17} \mathrm{O} / 10^{3}\right)$ vs. $10^{3} \ln \left(1+\delta^{18} \mathrm{O} / 10^{3}\right)$ plot, the same VSMOW-SLAP scaling factor should hold for ${ }^{17} \mathrm{O}$. The scaling factor is simply given by $-57.10 /-56.20=1.0160$, where $-57.10=10^{3} \ln \left(1+(-55.5) / 10^{3}\right)$ for SLAP and $-56.20=10^{3} \ln \left(1+(-54.65) / 10^{3}\right)$, calculated from the observed $\delta^{18} \mathrm{O}_{\text {VSMOw }}$ of SLAP. This way of VSMOWSLAP scaling is more reasonable than using a ratio of $-55.5 / \delta^{18} \mathrm{O}_{\mathrm{SLAP}-\mathrm{observed}}$ as initially recommended by IAEA (Gonfiantini, 1978). The values of $10^{3} \ln \left(1+\delta^{17} \mathrm{O}_{\text {VSMOW- }}\right.$ SLAP $\left./ 10^{3}\right)$ and $10^{3} \ln \left(1+\delta^{18} \mathrm{O}_{\mathrm{VSMOW}-\mathrm{SLAP}} / 10^{3}\right)$ in Table 1 (columns 11 and 12) were obtained by multiplying the scaling factor of 1.0160 to the values of $10^{3} \ln (1+$ $\left.\delta^{17} \mathrm{O}_{\mathrm{VSMOW}} / 10^{3}\right)$ and $10^{3} \ln \left(1+\delta^{18} \mathrm{O}_{\mathrm{VSMOW}} / 10^{3}\right)$ (columns 9 and 10), respectively. Assuming the same scaling fac- 
tor can be applied to silicate samples that have generally $\delta$ values higher than those of waters, this practice resulted in $\delta^{17} \mathrm{O}$ and $\delta^{18} \mathrm{O}$ values on the VSMOW-SLAP scale as given in columns 13 and 14 , respectively.

Figure 2 shows plots of $10^{3} \ln \left(1+\delta^{17} \mathrm{O}_{\mathrm{VSMOW}-\mathrm{SLAP}} /\right.$ $\left.10^{3}\right)$ vs. $10^{3} \ln \left(1+\delta^{18} \mathrm{O}_{\text {VSMOW-SLAP }} / 10^{3}\right)$ for waters (Fig. 2a) and for silicates and oxides (Fig. 2b). We have separated the waters from silicates, because the slope of the regression line $\lambda$ is likely different as stated above. The waters (VSMOW, GISP, SLAP and MSA6 (a laboratory standard)) plot on a regression line with a slope of 0.528 \pm 0.001 (standard error at $95 \%$ confidence limit). This value is in good agreement with $\lambda$ values for waters reported by Meijer and Li (1998) and Barkan and Luz (2005), confirming that meteoric waters are characterized by $\lambda=0.528$. The silicate and oxide samples with $\delta^{18} \mathrm{O}$ values ranging from $-6.5 \%$ to $10.5 \%$ (Table 1 ) plot on a regression line with $\lambda=0.526 \pm 0.003$. The standard error at $95 \%$ confidence limit for the silicates and oxides is greater than that for water, probably because a span of the $\delta^{18} \mathrm{O}$ values of the silicate and oxide samples used here $\left(17 \%\right.$ in $\left.\delta^{18} \mathrm{O}\right)$ is narrower than that for the waters $\left(55 \%\right.$ in $\left.\delta^{18} \mathrm{O}\right)$, and poor analytical reproducibility of enstatite and fayalite relative to the others (Table 1). If our standard error at $95 \%$ confidence limit for the slope $( \pm 0.003)$ is taken into account, our $\lambda$ value of 0.526 is consistent with the $\lambda$ value of $0.524 \pm 0.001$ for silicates reported by Miller (2002), Pack et al. (2007) and Rumble et al. (2007). The above statement that waters and silicates appear to have different $\lambda$ values confirms that $\lambda$ values are process-dependent as initially pointed out by Matsuhisa et al. (1978), because mechanisms of natural isotopic variations for water (e.g., evaporation, condensation, diffusion) are quite different from those for silicates and oxides (e.g., crystallization, melting, fluid-rock interaction). Thus precisely determined $\lambda$ values will be used to clarify the processes in which oxygen isotopic variations have taken place as suggested in Luz and Barkan (2005) and Rumble et al. (2007).

As shown in Table 1 , the $\delta^{17} \mathrm{O}$ value of SLAP, which has rarely been reported, is $-29.67 \pm 0.07 \%$ on the VSMOW-SLAP scale. The value given by Barkan and Luz (2005) is -29.48\%o, which becomes -29.69\%o if VSMOWSLAP scaled. Our $\delta^{17} \mathrm{O}_{\text {VSMOW-SLAP }}$ and $\delta^{18} \mathrm{O}_{\text {VSMOW-SLAP }}$ values for GISP were calculated likewise to be $-13.11 \pm$ $0.08 \%$ and $-24.80 \pm 0.07 \%$, respectively. They agree quite well with the Barkan and Luz (2005) values and also with the reported $\delta^{18} \mathrm{O}$ value for GISP (Gonfiantini et al., 1995).

It is well known that extraterrestrial materials do not follow the above mentioned mass-dependent fractionation (e.g., Clayton, 1993). The deviation from the terrestrial fractionation line is expressed by $\Delta^{17} \mathrm{O}$ which is often expressed by $\Delta^{17} \mathrm{O}_{\mathrm{C}}=\delta^{17} \mathrm{O}-0.52 \times \delta^{18} \mathrm{O}$ (Clayton, 1993 , the subscript $\mathrm{C}$ of $\Delta^{17} \mathrm{O}_{\mathrm{C}}$ stands for Clayton). The "accuracy" of $\Delta^{17} \mathrm{O}_{\mathrm{C}}$ becomes increasingly worse as $\delta^{18} \mathrm{O}$ value goes away from that used for a standard. If a new definition of the big delta is taken as $\Delta^{17} \mathrm{O}_{\mathrm{M}}=10^{3} \ln \left(1+\delta^{17} \mathrm{O} /\right.$ $\left.10^{3}\right)-\lambda \times 10^{3} \ln \left(1+\delta^{18} \mathrm{O} / 10^{3}\right)$ (Miller, 2002, the subscript $\mathrm{M}$ of $\Delta^{17} \mathrm{O}_{\mathrm{M}}$ stands for Miller), the accuracy of $\Delta^{17} \mathrm{O}_{\mathrm{M}}$ is guaranteed for a much wider range of $\delta^{18} \mathrm{O}$. Of course, the magnitude of $\Delta^{17} \mathrm{O}_{\mathrm{M}}$ thus calculated depends on $\lambda$. Considering a small difference of $\lambda$ values for waters and silicates as stated above, $\Delta{ }^{17} \mathrm{O}_{\mathrm{M}}$ values of our samples have been calculated using $\lambda=0.528$ for waters and $\lambda=0.526$ for silicates and oxides in Table 1 . Although our $\lambda$ for silicates is slightly greater than the value $(0.524)$ proposed by Miller (2002), Pack et al. (2007) and Rumble et al. (2007), the $\Delta^{17} \mathrm{O}_{\mathrm{M}}$ values are close to zero with few exceptions and can be used to evaluate the offset of most extraterrestrial materials from the terrestrial fractionation line.

\section{Conclusions}

Oxygen isotopic ratios of natural waters have been reported on the VSMOW-SLAP scale as recommended by IAEA. Since $\delta^{18} \mathrm{O}$ values of silicates and oxides are usually calculated relative to VSMOW through indirect ways, e.g., adoption of a given silicate reference material of which oxygen isotopic value has been published or comparison of $\delta^{18} \mathrm{O}$ of $\mathrm{CO}_{2}$ with that derived from international reference waters and carbonates. To avoid any uncertainties potentially involved in such indirect ways, we recommend to measure oxygen isotopic ratios of $\mathrm{O}_{2}$ directly derived from VSMOW and SLAP at the same time when oxygen isotopic ratio of silicates are measured. From the data obtained the oxygen isotopic ratios should be reported on the VSMOW-SLAP scale as we did. Such exercise is particularly important for international reference silicate materials such as NBS-28 quartz and NBS30 in the community of oxygen isotope geochemists, for they are often taken as a reference material for reporting on the VSMOW basis. Based on our results a choice of the $\mathrm{CO}_{2}-\mathrm{H}_{2} \mathrm{O}$ fractionation factor of 1.0407 is recommended, if oxygen isotopic ratios are referred to that of VSMOW using a conventional system with $\mathrm{CO}_{2}$ as the analyzing gas.

When the "big delta" $\left(\Delta^{17} \mathrm{O}\right)$ of sample under consideration, a deviation of $\delta^{17} \mathrm{O}$ from the terrestrial fractionation line, is calculated using equation $\Delta^{17} \mathrm{O}=10^{3}$ $\ln \left(1+\delta^{17} \mathrm{O} / 10^{3}\right)-\lambda \times 10^{3} \ln \left(1+\delta^{18} \mathrm{O} / 10^{3}\right)$ as given by Miller (2002), the most appropriate proportionality constant $\lambda$ has to be chosen, for it is depending on the isotopic fractionation process concerned.

Acknowledgments - The authors thank T. Nogi for her technical support during $\delta^{17} \mathrm{O}-\delta^{18} \mathrm{O}$ analysis. We acknowledge three 
reviewers (M. Miller, R. N. Clayton and Y. Sano) for their detailed and constructive comments on the earlier version of the manuscript. We also thank M. Miller for drawing our attention to some literatures directly related to this work. Mineral separates used in this study were supplied by T. Nakamura, T. Yada, T. Hiyagon and T. Ushikubo. This work was partially supported by the 2002-2004 Grant-in-Aid No. 14340172 to M.K. from Japan Society for the Promotion of Science and by Korea Polar Research Institute (Project PE07020).

\section{REFERENCES}

Akagi, T., Franchi, I. A. and Pillinger, C. T. (1995) Isotope analysis of oxygen in minerals using Nd/YAG laserfluorination: the use of stainless-steel wool trap as a fluorine remover. Geochem. J. 29, 115-122.

Baertschi, P. (1976) Absolute ${ }^{18} \mathrm{O}$ content of Standard Mean Ocean Water. Earth Planet. Sci. Lett. 31, 341-344.

Barkan, E. and Luz, B. (2005) High precision measurements of ${ }^{17} \mathrm{O} /{ }^{16} \mathrm{O}$ and ${ }^{18} \mathrm{O} /{ }^{16} \mathrm{O}$ ratios in $\mathrm{H}_{2} \mathrm{O}$. Rapid Commun. Mass Spetrom. 19, 3737-3742.

Chako, T., Cole, D. R. and Horita, J. (2001) Equilibrium oxygen, hydrogen and carbon isotope fractionation factors applicable to geological systems. Chapt. 1 in Rev. Mineral. Geochem. Vol. 43 (Valley, J. W. and Cole, D. R., eds.), Mineralogical Society of America.

Clayton, R. N. (1993) Oxygen isotopes in meteorites. Annual Rev. Earth Planet. Sci. 21, 115-149.

Clayton, R. N. and Mayeda, T. K. (1963) The use of bromine pentafluoride in the extraction of oxygen from oxides and silicates for isotopic analysis. Geochim. Cosmochim. Acta 27, 43-52.

Clayton, R. N. and Mayeda, T. K. (1983) Oxygen isotopes in eucrites, shergottites, nakhlites, and chassignites. Earth Planet. Sci. Lett. 62, 1-6.

Clayton, R. N., Grossman, L. and Mayeda, T. K. (1973) A component of primitive nuclear composition in carbonaceous meteorites. Science 182, 485.

Coplen, T. B. (1988) Normalization of oxygen and hydrogen isotope data. Chem. Geol. (Isotope Geoscience Section) 72, 293-297.

Coplen, T. B. (1995) Discontinuance of SMOW and PDB. Nature 375, 285.

Coplen, T. B., Kendall, C. and Hopple, J. (1983) Comparison of stable isotope reference samples. Nature 302, 236-238.

Craig, H. (1961) Standard for reporting concentrations of deuterium and oxygen-18 in natural waters. Science 133, 18331834.

Eiler, J. M., Valley, J. W. and Stolper, E. M. (1996) Oxygen isotope ratios in olivine from the Hawaii Scientific Drilling Project. J. Geophys. Res. 101, 11807-11813.

Elsenheimer, D. and Valley, J. W. (1993) Submillimeter scale zonation of $\delta^{18} \mathrm{O}$ in quartz and feldspar, Isle of Skye, Scotland. Geochim. Cosmochim. Acta 57, 3669-3676.

Epstein, S. and Mayeda, T. (1953) Variation of $\mathrm{O}^{18}$ content of waters from natural sources. Geochim. Cosmochim. Acta $\mathbf{4}$, 213-224.

Fouillac, A.-M. and Girard, J.-P. (1996) Laser oxygen isotope analysis of silicate/oxide grain separates: Evidence fro a grain size effect? Chem. Geol. 130, 31-54.

Franchi, I. A., Wright, I. P., Sexton, A. S. and Pillinger, C. T. (1999) The oxygen-isotopic composition of Earth and Mars. Meteorit. Planet. Sci. 34, 657-661.

Friedman, I. and Gleason, J. D. (1973) Notes on the bromine pentafluoride technique of oxygen extraction. J. Res. U.S. Geol. Survey 1, 679-680.

Friedman, I. and O'Neil, J. R. (1977) Compilation of stable isotope fractionation factors of geochemical interest. Data of Geochemistry, Sixth Edition. Chapter KK, Geological Survey Professional Paper 440-KK.

Gonfiantini, R. (1978) Standards for stable isotope measurements in natural compounds. Nature 271, 534-536.

Gonfiantini, R. (1984) Advisory Group Meeting on Stable Isotope Reference Samples for Geochemical and Hydrological Investigations, Vienna, 19-21 September 1983. Rep. to Dir. Gen., Int. At. Energy Agency, Vienna, 77 pp.

Gonfiantini, R., Stichler, W. and Rozanski, K. (1995) Standards and intercomparison materials distributed by the International Atomic Energy Agency for stable isotope measurements. IAEA-TECDOC-825, p. 13-29.

Horibe, Y. (1966) Measurement of isotopic ratio of light elements. J. Mass Spectrom. Soc. Jpn. 14, 113-120 (in Japanese).

Hut, G. (1987) Consultants' Group Meeting on Stable Isotope Reference Samples for Geochemical and Hydrological Investigations. Vienna, 16-18 September 1985. Rep. to Dir. Gen., International Atomic Energy Agency, Vienna, 42 pp.

Ito, E. and Clayton, R. N. (1983) Submarine metamorphism of gabbros from the Mid-Cayman Rise: and oxygen isotopic study. Geochim. Cosmochim. Acta 47, 535-546.

Jabeen, I. and Kusakabe, M. (1997) Determination of $\delta^{17} \mathrm{O}$ values of reference water samples VSMOW and SLAP. Chem. Geol. 142, 115-119.

Jabeen, I. Kusakabe, M., Nagao, K. and Nakamura, T. (1998) Oxygen isotope study of Tsukuba chondrite, some HED meteorites and Allende chondrules. Antarct. Meteorite Res. 11, 122-135.

Kusakabe, M., Maruyama, S., Nakamura, T. and Yada, T. (2004) $\mathrm{CO}_{2}$ laser- $\mathrm{BrF}_{5}$ fluorination technique for analysis of oxygen three isotopes of rocks and minerals. J. Mass Spectrom. Soc. Jpn. 52, 205-212.

Larson, T. E. and Sharp, Z. D. (2005) Interpreting progradegrowth histories of $\mathrm{Al}_{2} \mathrm{SiO}_{5}$ triple-point rocks using oxygen-isotope thermometry: an example from the Truchas Mountains, USA. J. Metamorphic Geol. 23, 847-863.

Li, W., Ni, B., Jin, D. and Zhang, Q. (1988) Measurement of the absolute abundance of oxygen-17 in V-SMOW. Kexue Tongbao 33 (No. 19), 1610-1613.

Luz, B. and Barkan, E. (2005) The isotopic ratios ${ }^{17} \mathrm{O} /{ }^{16} \mathrm{O}$ and ${ }^{18} \mathrm{O} /{ }^{16} \mathrm{O}$ in molecular oxygen and their significance in biogeochemistry. Geochim. Cosmochim. Acta 69, 1099-1110.

Matsuhisa, Y. and Aoki, M. (1993) Temperature and oxygen isotope variations during formation of the Hishikari epithermal gold-silver veins, southern Kyushu, Japan. Econ. Geol. 89, 1608-1613.

Matsuhisa, Y., Goldsmith, J. R. and Clayton, R. N. (1978) Mechanisms of hydrothermal crystallization of quartz at $250^{\circ} \mathrm{C}$ and 15 kbar. Geochim. Cosmochim. Acta 42, 173- 
182.

Mattey, D. and Macpherson, C. (1993) High-precision oxygen isotope microanalysis of ferromagnesian minerals by laserfluorination. Chem. Geol. 105, 305-318.

Meijer, H. A. and Li, W. J. (1998) The use of electrolysis for accurate $\delta^{17} \mathrm{O}$ and $\delta^{18} \mathrm{O}$ isotope measurements in water. Isotopes. Environ. Health Stud. 34, 349-369.

Miller, M. (2002) Isotopic fractionation and quantification of ${ }^{17} \mathrm{O}$ anomalies in the oxygen three-isotope system: an appraisal and geochemical significance. Geochim. Cosmochim. Acta, 66, 1881-1889.

Miller, M. F., Franchi, I. A., Sexton, A. S. and Pillinger, C. T. (1999) High precision $\delta^{17} \mathrm{O}$ isotope measurements of oxygen from silicates and other oxides: Method and applications. Rapid Commun. Mass Spetrom. 13, 1211-1217.

Pack, A., Toulouse, C. and Przybilla, R. (2007) Determination of oxygen triple isotope ratios of silicates without cryogenic separation of $\mathrm{NF}_{3}$ - technique with application to analyses of technical $\mathrm{O}_{2}$ gas and meteorite classification. Rapid Commun. Mass Spetrom. 21, 3721-3728.

Rumble, D., III and Hoering, T. C. (1994) Analysis of oxygen and sulfur isotope ratios in oxide and sulfide minerals by spot heating with a carbon dioxide laser in a fluorine atmosphere. Acc. Chem. Res. 27, 237-241.

Rumble, D., III, Farquhar, J., Young, E. D. and Christensen, C.
P. (1997) In situ oxygen isotope analysis with an excimer laser using $\mathrm{F}_{2}$ and $\mathrm{BrF}_{5}$ reagents and $\mathrm{O}_{2}$ gas as analyte. Geochim. Cosmochim. Acta 61, 4229-4234.

Rumble, D., Miller, M. F., Franchi, I. A. and Greenwood, R. C. (2007) Oxygen three-isotope fractionation lines in terrestrial silicate minerals: An inter-laboratory comparison of hydrothermal quartz and eclogite garnet. Geochim. Cosmochim. Acta 71, 3592-3600.

Sharp, Z. D. (1990) A laser-based microanalytical method for the in-situ determination of oxygen isotope ratios of silicates and oxides. Geochim. Cosmochim. Acta 54, 13531357.

Spicuzza, M. J., Valley, J. W., Kohn, M. J., Girard, J. P. and Fouillac, A. M. (1998) The rapid heating, defocused beam technique: a $\mathrm{CO}_{2}$-laser-based method for highly precise and accurate determination of $\delta^{18} \mathrm{O}$ values of quartz. Chem. Geol. 144, 195-203.

Taylor, B. E. (2005) Fluorination methods in stable isotope analysis. Handbook of Stable Isotope Analytical Techniques (Pier de Groot, ed.), Chapt. 20, Elsevier Publications.

Valley, J. W., Kitchen, N., Kohn, M. J., Niendorf, C. R. and Spicuzza, M. J. (1995) UWG-2, a garnet standard for oxygen isotope ratios: Strategies for high precision and accuracy with laser heating. Geochim. Cosmochim. Acta 59, 5223-5231. 